\title{
Diagnostic value of VDBP and miR-155-5p in diabetic nephropathy and the correlation with urinary microalbumin
}

\author{
XU BAI, QUN LUO, KUIBI TAN and LIMING GUO \\ Department of Nephrology, HwaMei Hospital, \\ University of Chinese Academy of Sciences, Ningbo, Zhejiang 315000, P.R. China
}

Received September 30, 2019; Accepted June 5, 2020

DOI: $10.3892 /$ etm.2020.9214

\begin{abstract}
This study explored the diagnostic and therapeutic significance of vitamin D binding protein (VDBP) and miR-155-5p for diabetic nephropathy and the correlation with urinary microalbumin. A total of 145 patients with type 2 diabetes who attended the Hwamei hospital were selected as research objects and assigned to diabetic nephropathy group (DN group) and diabetes group according to whether they suffered from diabetic nephropathy (DN). The expression levels of urine VDBP and serum miR-155-5p in the two groups were detected, and the correlation between urinary microalbumin (mAlb), serum cystatin C (Cys C) and 24-h urinary protein was analyzed. The predictive value of single and joint detection of urinary VDBP and serum miR-155-5p for DN onset and poor prognosis was analyzed. In DN patients, urine VDBP and serum miR-155-5p were highly expressed, and urine VDBP, serum miR-155-5p and mAlb, Cys C and 24-h urine protein were positively correlated $(\mathrm{P}<0.05)$. Moreover, the joint detection of urine VDBP and serum miR-155-5p was more valuable in diagnosis and poor prognosis prediction of DN patients than its single detection. Urine VDBP and serum miR-155-5p have good diagnostic value for DN, but their joint diagnostic value is higher, and their expression levels are all related to mAlb of DN patients, which may be used as new biological indicators for diagnosis and disease assessment.
\end{abstract}

\section{Introduction}

Diabetic nephropathy (DN) is one of the main complications of diabetic microangiopathy and one of the main causes of uremia. The morbidity and mortality of DN in diabetic patients are both high, which is a serious threat to their quality of life and health $(1,2)$. Clinically, the early symptoms of DN onset are not obvious, and the indicator changes are usually

Correspondence to: Dr Liming Guo, Department of Nephrology, HwaMei Hospital, University of Chinese Academy of Sciences, 41 Xibei Street, Ningbo, Zhejiang 315000, P.R. China

E-mail: guoliming2008@126.com

Key words: VDBP, miR-155-5p, diabetic nephropathy, diagnostic value, urinary microalbumin, correlation not obvious in routine detection, therefore difficult to detect. However, in the late stage, the disease progresses very quickly, and the liver and kidney functions also decline rapidly, which will also lead to poor prognosis due to lack of timely treatment $(3,4)$. Therefore, for DN patients, early diagnosis and timely treatment have important clinical significance.

Vitamin D binding protein (VDBP) belongs to the binding protein albumin family. It is mainly synthesized by liver and then reabsorbed by proximal tubular epithelial cells after glomerular filtration (5). Previous studies confirmed that urine VDBP was a new biomarker of tubulointerstitial injury independent of proteinuria, and it mainly appeared in the early stage of inflammatory reaction and tubulointerstitial fibrosis and had high sensitivity to renal inflammation (6). Inflammation played a vital role in the pathogenesis of DN (7). In addition, previous studies found that abundant miRNA expression could be seen in kidney tissues of DN patients, and reported that its expression could reflect the condition of patients to a certain extent, and that miRNA and DN were closely related (8). miR-155-5p is a miRNA that plays an important regulatory role in the development and progression of tumors, and its diagnostic and prognostic value in tumors has also been confirmed (9). Previous study also discovered that miR-155-5p was highly expressed in DN, and it was considered that its expression was tied to the severity of DN patients (10).

However, there is relatively scarce research on the diagnostic value of VDBP and miR-155-5p in DN at present, so we explored the diagnostic value of VDBP and miR-155-5p in $\mathrm{DN}$, and analyzed the correlation between VDBP and urinary microalbumin (mAlb) (11), which is the main basis indicator for $\mathrm{DN}$ diagnosis to provide more reference schemes.

\section{Patients and methods}

General information. From April 2015 to January 2017, 145 patients with type 2 diabetes were selected as research targets, including 75 male patients and 70 female patients. Their average age was $(68.02 \pm 5.33)$ years, including $71 \mathrm{DN}$ patients (DN group) and 74 non-DN patients (diabetes group). Inclusion criteria were as follows: Patients who met the diagnostic criteria for type 2 diabetes of the American Diabetes Association (12). Patients diagnosed as DN by pathological (biopsy) diagnosis were included in DN group. Exclusion criteria were as follows: patients with primary renal diseases, 
Table I. General data.

\begin{tabular}{|c|c|c|c|c|}
\hline Factor & $\mathrm{DN}$ group $(\mathrm{n}=71)$ & Diabetes group $(\mathrm{n}=74)$ & $\mathrm{t} / \chi^{2}$ value & P-value \\
\hline Sex & & & 0.008 & 0.927 \\
\hline Male & $37(52.11)$ & $38(51.35)$ & & \\
\hline Female & $34(47.89)$ & $36(48.65)$ & & \\
\hline Age, years) & & & 0.003 & 0.959 \\
\hline$\leq 68$ & $31(43.66)$ & $32(43.24)$ & & \\
\hline$>68$ & $40(56.34)$ & $42(56.76)$ & & \\
\hline $\mathrm{BMI}, \mathrm{kg} / \mathrm{m}^{2}$ & & & 0.007 & 0.932 \\
\hline$\leq 23$ & $36(50.70)$ & $37(50.00)$ & & \\
\hline$>23$ & $35(49.30)$ & $37(50.00)$ & & \\
\hline Educational level & & & 0.011 & 0.916 \\
\hline Below junior high school & $32(45.07)$ & $34(45.95)$ & & \\
\hline Junior high school and above & $39(54.93)$ & $40(54.05)$ & & \\
\hline Place of residence & & & 0.000 & 0.987 \\
\hline Countryside & $45(63.38)$ & $47(63.51)$ & & \\
\hline City or town & $26(36.62)$ & $27(36.49)$ & & \\
\hline Fasting blood glucose $(\mathrm{mmol} / \mathrm{l})$ & $8.35 \pm 1.58$ & $8.47 \pm 1.53$ & 0.465 & 0.643 \\
\hline HbAlc (mmol/l) & $8.32 \pm 1.65$ & $8.41 \pm 1.74$ & 0.319 & 0.750 \\
\hline $\mathrm{SCr}(\mu \mathrm{mol} / \mathrm{l})$ & $93.21 \pm 21.66$ & $48.26 \pm 9.52$ & 16.29 & $<0.001$ \\
\hline UREA (mmol/l) & $8.67 \pm 1.18$ & $5.13 \pm 0.42$ & 24.26 & $<0.001$ \\
\hline
\end{tabular}

HbA1c, hemoglobin A1c; SCr, serum creatinine; UREA, blood urea; DN, diabetic nephropathy.

other diabetic complications, ketoacidosis or other metabolic diseases; patients who had used immunosuppressive agents or nephrotoxic drugs in the recent past; patients with malignant tumors, severe infectious diseases, other severe diabetic complications; patients who refused to participate in the study.

The study was approved by the Ethics Committee of HwaMei Hospital (Ningbo, China). All patients and their families agreed to participate in the study and signed informed consents were obtained from the patients and/or their guardians.

\section{Indicator detection}

$R T-P C R$ detection of miR-155-5p expression. Venous blood $(3 \mathrm{ml})$ of all patients was drawn on an empty stomach, and then centrifuged for $10 \mathrm{~min}$ at $8,000 \mathrm{x} \mathrm{g}$ at $4^{\circ} \mathrm{C}$. Serum was taken for detection, and total RNA in serum was extracted with TRIzol reagent (15596018; Thermo Fisher Scientific). The purity and concentration of RNA were detected with ultraviolet spectrophotometer, and then $5 \mu \mathrm{g}$ of total RNA was taken, respectively, and reverse transcription cDNA was performed following the instructions of the reverse transcription kit (AQ202-01; TransGen Biotech). The reaction parameters were as follows: $37^{\circ} \mathrm{C}$ for $10 \mathrm{~min}, 45^{\circ} \mathrm{C}$ for $30 \mathrm{~min}$, $72^{\circ} \mathrm{C}$ for 4 min. miR-155-5p amplification system (PCR kit; AQ201-01; TransGen Biotech): cDNA $1 \mu 1$, upstream and downstream primers $0.4 \mu 1$ each, 2X TransTaq ${ }^{\circledR}$ Tip Green qPCR SuperMix $10 \mu 1$, Passive Reference Dye (50X) $0.4 \mu 1$, $\mathrm{ddH}_{2} \mathrm{O}$ supplemented to $20 \mu \mathrm{l}$. Amplification conditions: PCR reaction conditions were as follows: Pre-denaturation at $94^{\circ} \mathrm{C}$ for $45 \mathrm{sec}$, denaturation at $94^{\circ} \mathrm{C}$ for $10 \mathrm{sec}$, annealing extension at $60^{\circ} \mathrm{C}$ for $45 \mathrm{sec}$, a total of 40 cycles. Each sample was provided with 3 repeated wells, and the experiment was carried out 3 times. U6 was used as the internal reference and $2^{-\Delta \Delta c t}$ was used to analyze the data.

Detection of VDBP, mAlb and other biochemical indicators. Urine VDBP (m1023696; Shanghai Enzyme Linked Biotechnology Co., Ltd.) was detected by ELISA and mAlb was detected by immunoturbidimetry. Fasting venous blood $(5 \mathrm{ml})$ of patients was drawn, and then centrifuged for $10 \mathrm{~min}$ at $8,000 \times \mathrm{g}$ at $4^{\circ} \mathrm{C}$. Serum was taken and the serum glycosylated hemoglobin A1c (HbAlc), serum creatinine (SCr), blood urea (UREA) and cystatin C (Cys C) were detected by automatic biochemical analyzer, and 24-h urine protein of patients was detected.

Statistical analysis. In this study, the experimental data were statistically analyzed via SPSS 19.0 software, the counting data were checked through Chi-square test, and the measurement data were assessed via mean \pm standard deviation. Moreover, t-test was employed for comparison between the two groups, GraphPad Prism 6 software was employed for drawing the experimental illustrations, and Pearson's was employed for correlation analysis. ROC results were analyzed via STATA software. SPSS was used to analyze data of the two groups, binary logistic analysis was used to calculate the predictive factors, and then ROC curve analysis was carried out to calculate the diagnostic sensitivity and specificity. Difference of $\mathrm{P}<0.05$ was considered to be statistically significant. 
Table II. Expression of serum miR-155-5p and urine VDBP.

\begin{tabular}{lcrr}
\hline Factor & DN group $(\mathrm{n}=71)$ & Diabetes group $(\mathrm{n}=74)$ & t value \\
\hline miR-155-5p & $3.25 \pm 1.53$ & $1.82 \pm 0.93$ & 6.832 \\
Urine VDBP $(\mathrm{ng} / \mathrm{ml})$ & $61.98 \pm 31.85$ & $22.51 \pm 9.16$ & 10.23 \\
\hline
\end{tabular}

VDBP, vitamin D binding protein; DN, diabetic nephropathy.

A

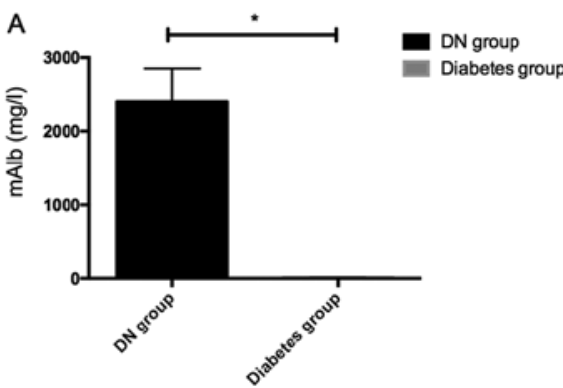

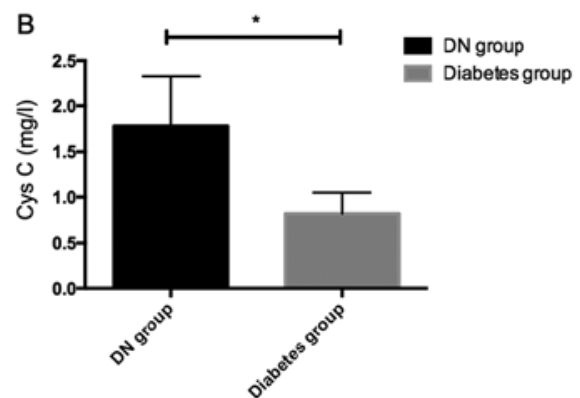

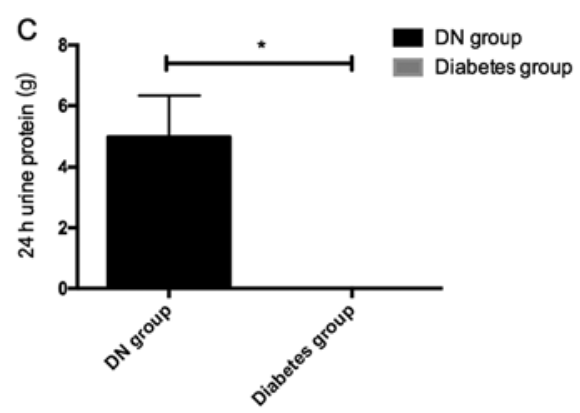

Figure 1. Detection of other relevant indicators of DN. (A) Urine mAlb level of patients in the two groups. (B) Serum Cys C level of patients in the two groups. (C) 24-h urine protein level of patients in the two groups. * $\mathrm{P}<0.05$. DN, diabetic nephropathy; mAlb, microalbumin; Cys C, cystatin C.

\section{Results}

General data. There was no significant difference in sex, age and BMI between the two groups $(\mathrm{P}>0.05)$, as shown in Table I.

Expression levels of serum miR-155-5p and urine VDBP. The expression levels of serum miR-155-5p and urine VDBP in the DN group were significantly higher than those in the diabetes group, with statistically significant difference $(\mathrm{P}<0.05)$, as shown in Table II.

Detection of other relevant indicators. In order to further compare differences between DN patients and non-DN patients, we further compared the expression levels of $\mathrm{mAlb}$, Cys $\mathrm{C}$ and 24-h urine protein of patients in the two groups. The results showed that $\mathrm{mAlb}, \mathrm{Cys} \mathrm{C}$ and 24 -h urine protein in the DN group were significantly higher than those in the diabetes group, with statistically significant differences $(\mathrm{P}<0.05)$, as shown in Fig. 1.

Correlation analysis of serum miR-155-5p, urine VDBP and $m A l b, C y s C$ and 24-h urine protein in DN patients. Serum miR-155-5p and mAlb, Cys C and 24-h urine protein in DN patients were positively correlated $(\mathrm{P}<0.05)$, while urine VDBP and mAlb, Cys C and 24-h urine protein were positively correlated $(\mathrm{P}<0.05)$, as shown in Table III and Fig. 2.

Diagnostic value of single and joint detection of serum miR-155-5p and urine VDBP in DN. The diagnostic sensitivity of miR-155-5p to DN was $75.68 \%$, specificity was $64.79 \%$, AUC was $0.746,95 \%$ CI was 0.664-0.828, and cut-off value was 2.6; the diagnostic sensitivity of urine VDBP to DN was $85.14 \%$, specificity was $83.10 \%$, AUC was $0.859,95 \%$ CI was $0.787-0.931$, and cut-off value was $31.24 \mathrm{ng} / \mathrm{ml}$; the diagnostic sensitivity of joint diagnosis of serum miR-155-5p and urine VDBP was $93.24 \%$, specificity was $76.06 \%$, AUC was 0.904 , and $95 \% \mathrm{CI}$ was 0.851-0.958. Although serum miR-155-5p and urine VDBP had certain diagnostic value for DN, the sensitivity and AUC of joint diagnosis were higher than that of single diagnosis, and the former had higher diagnostic value, as shown in Fig. 3.

Prognostic value of serum miR-155-5p and urine VDBP in poor prognosis of patients with DN. All DN patients were followed up for 2 years, among them 32 patients entered end-stage renal disease (ESRD) during the follow-up period. The serum miR-155-5p and urine VDBP of ESRD patients were significantly higher than those of ESRD patients without ESRD, with statistically significant difference $(\mathrm{P}<0.05)$. ROC curve showed that the sensitivity, specificity, AUC, 95\% CI and cut-off value of serum miR-155-5p were 74.36, $65.63 \%, 0.744,0.628-0.861,3.409,82.05$ and $71.88 \%$, respectively, for predicting poor prognosis of DN patients. AUC was $0.849,95 \%$ CI was $0.759-0.939$, and the cut-off value was $62.06 \mathrm{ng} / \mathrm{ml}$. The sensitivity of joint detection of serum miR-155-5p and urine VDBP to predict poor prognosis of DN patients was $89.74 \%$, specificity was $65.63 \%$, AUC was 0.886 , 95\% CI was 0.810-0.963, and the joint detection had higher prediction value for poor prognosis of DN patients, as shown in Table IV and Fig. 4.

\section{Discussion}

Clinically, pathogenesis of DN has a relatively complicated mechanism, and its occurrence is also a common cause of renal failure. However, if diagnosis and treatment can be carried out as soon as possible, the progression of patients can be delayed or even reversed $(13,14)$. Therefore, it is of great clinical significance to find a diagnosis method with high sensitivity and specificity for DN patients. 
Table III. Correlation analysis of serum miR-155-5p, urine VDBP and mAlb, Cys C and 24-h urine protein in DN patients.

\begin{tabular}{|c|c|c|c|c|}
\hline \multirow[b]{2}{*}{ Indicators } & \multicolumn{2}{|c|}{ Serum miR-155-5p } & \multicolumn{2}{|c|}{ Urine VDBP } \\
\hline & r value & $\mathrm{P}$-value & r value & $\mathrm{P}$-value \\
\hline mAlb & 0.676 & $<0.001$ & 0.807 & $<0.001$ \\
\hline Cys C & 0.649 & $<0.001$ & 0.772 & $<0.001$ \\
\hline 24-h urine protein & 0.700 & $<0.001$ & 0.823 & $<0.001$ \\
\hline
\end{tabular}

VDBP, vitamin D binding protein; mAlb, microalbumin; Cys C, cystatin C; DN, diabetic nephropathy.
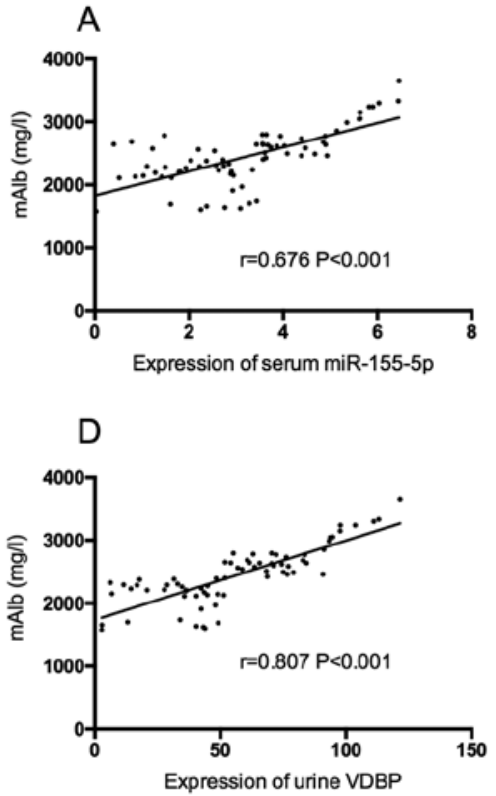
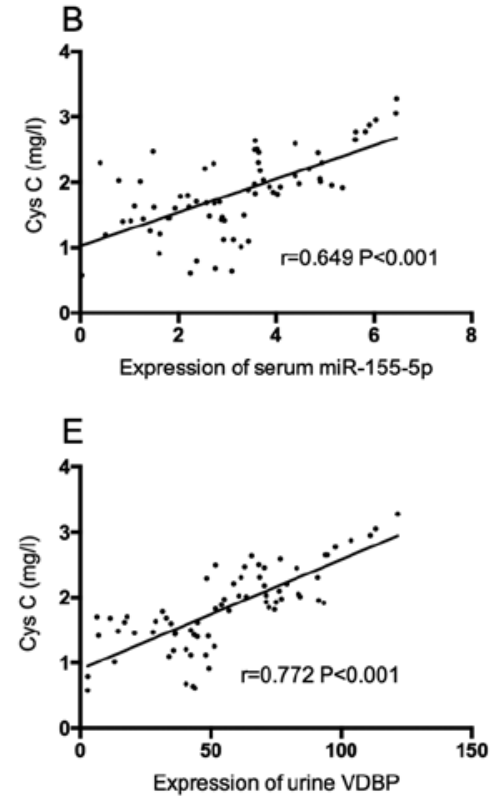
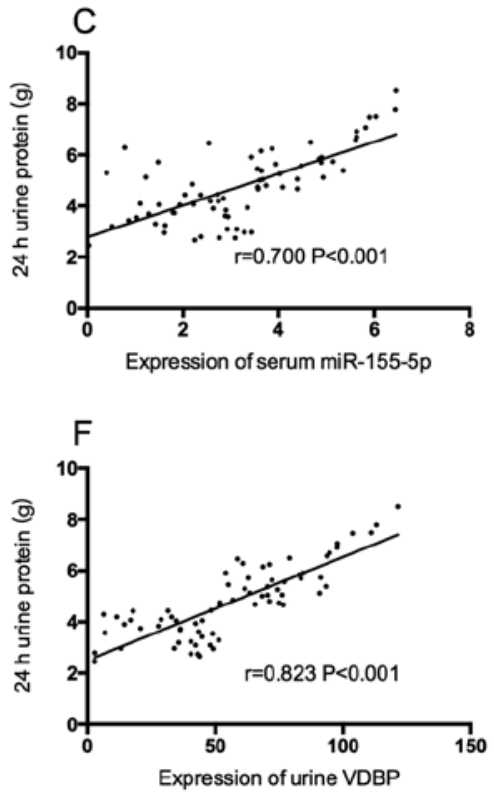

Figure 2. Correlation analysis of serum miR-155-5p, urine VDBP, mAlb, Cys C and 24-h urine protein in DN patients. (A) miR-155-5p and mAlb were positively correlated. (B) miR-155-5p and Cys C were positively correlated. (C) miR-155-5p was positively correlated with $24-\mathrm{h}$ urine protein. (D) Urine VDBP and mAlb were positively correlated. (E) Urine VDBP was positively correlated with Cys C. (F) There was a positive correlation between urine VDBP and 24-h urine protein. VDBP, vitamin D binding protein; mAlb, microalbumin; Cys C, cystatin C; DN, diabetic nephropathy.

A

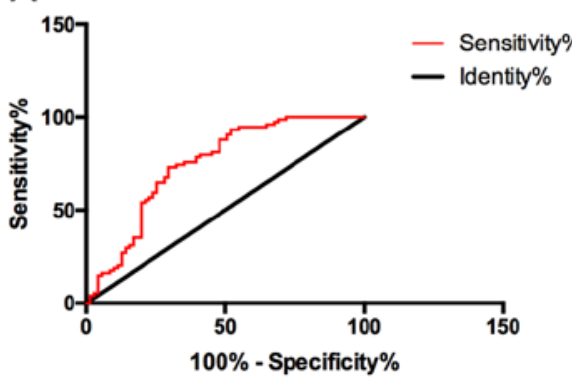

B

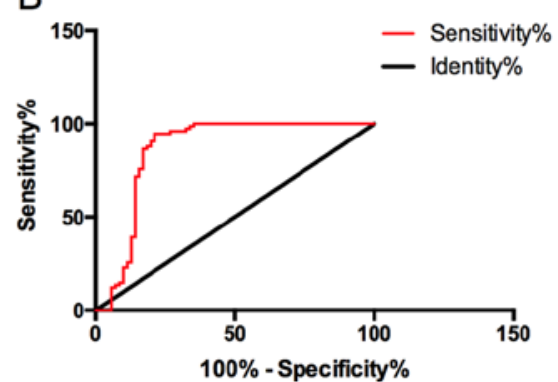

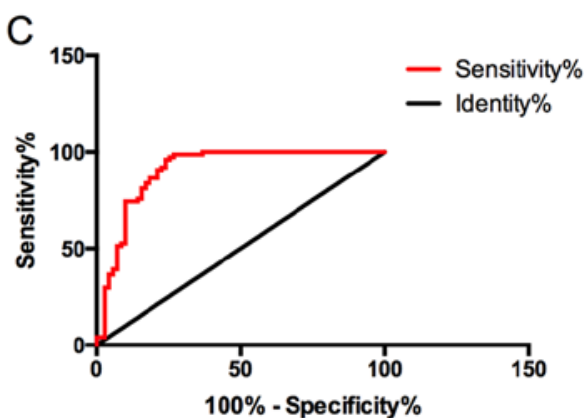

Figure 3. Diagnostic value of single and joint detection of serum miR-155-5p and urine VDBP in DN. (A) The diagnostic sensitivity of serum miR-155-5p to DN was $75.68 \%$, specificity was $64.79 \%$, AUC was $0.746,95 \%$ CI was $0.664-0.828$, and cut-off value was 2.6 . (B) The diagnostic sensitivity of urine VDBP to DN was $85.14 \%$, specificity was $83.10 \%$, AUC was $0.859,95 \%$ CI was $0.787-0.931$, and the cut-off value was 31.24 ng/ml. (C) The diagnostic sensitivity of joint diagnosis of serum miR-155-5p and urine VDBP for DN was $93.24 \%$, specificity was $76.06 \%$, AUC was 0.904 , and 95\% CI was $0.851-0.958$. VDBP, vitamin D binding protein; DN, diabetic nephropathy.

In the present study, it was first found that urine VDBP and serum miR-155-5p in DN patients were higher than those in diabetic patients, which suggested that both urine VDBP and serum miR-155-5p might be tied to the pathogenesis of DN.
As a glycosylated $\alpha$-globulin, VDBP is mainly synthesized by liver and filtered by glomerulus. In addition to binding and transporting vitamin $\mathrm{D}$ and its metabolic products, it can also be converted into an activating factor of macrophages to 
Table IV. Expression of serum miR-155-5p and urine VDBP in DN patients with different prognosis.

\begin{tabular}{lcrr}
\hline Factor & ESRD group $(\mathrm{n}=32)$ & Non-ESRD group $(\mathrm{n}=39)$ & t value \\
\hline miR-155-5p & $4.06 \pm 1.09$ & $2.82 \pm 0.88$ & 5.305 \\
Urine VDBP $(\mathrm{ng} / \mathrm{ml})$ & $73.82 \pm 24.25$ & $43.58 \pm 18.93$ & $<.706$ \\
\hline
\end{tabular}

VDBP, vitamin D binding protein; DN, diabetic nephropathy; ESRD, end-stage renal disease.
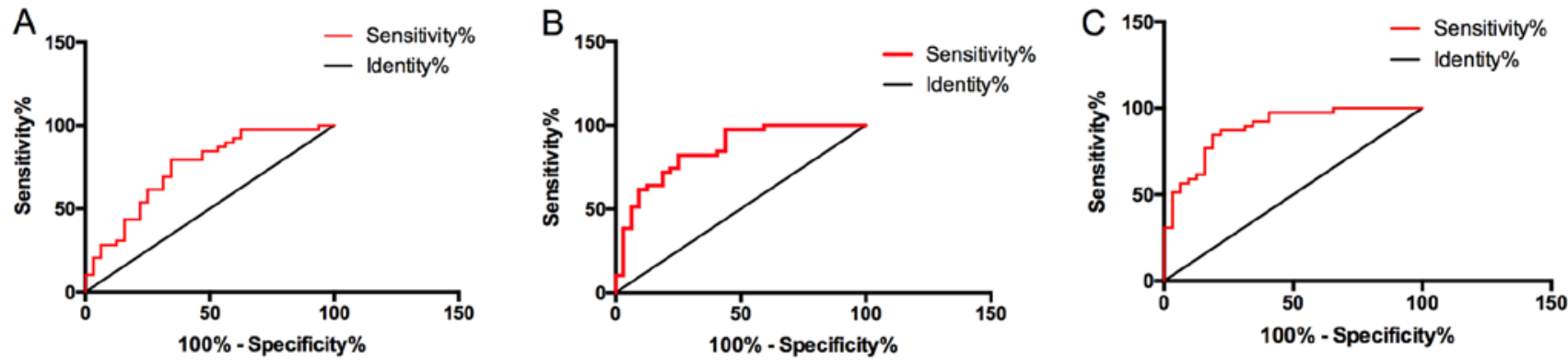

Figure 4. Predictive value of serum miR-155-5p and urine VDBP for poor prognosis of DN patients. (A) The predictive sensitivity of serum miR-155-5p to the occurrence of ESRD was $74.36 \%$, specificity was $65.63 \%$, AUC was $0.744,95 \%$ CI was $0.628-0.861$, and cut-off value was 3.409 . (B) The predictive sensitivity of urine VDBP to the occurrence of ESRD was $782.05 \%$, specificity was $71.88 \%$, AUC was $0.849,95 \%$ CI was $0.759-0.939$, and the cut-off value was $62.06 \mathrm{ng} / \mathrm{ml}$. (C) The predictive sensitivity of joint detection of serum miR-155-5p and urine VDBP for the occurrence of ESRD was $89.74 \%$, specificity was $65.63 \%$, AUC was 0.886 , and 95\% CI was 0.810-0.963. VDBP, vitamin D binding protein; DN, diabetic nephropathy; ESRD, end-stage renal disease.

promote polarization of macrophages $(15,16)$. The increase of VDBP is bound with the injury degree of tubulointerstitium and inflammatory reaction (17). However, miR, as a non-coding microRNA, was revealed previously to exert a crucial influence on the development and progression of DN by regulating various mechanisms, which suggested that it might be a target for diagnosis and treatment of DN (18). These studies also confirmed our conclusion. Subsequently, in order to further explore the clinical value of urine VDBP and serum miR-155-5p on DN, other DN-related indicators were also detected, mAlb, Cys C and 24-h urine protein, and the correlation between them and urine VDBP as well as serum miR-155-5p were analyzed; the results showed that mAlb, Cys $\mathrm{C}$ and 24-h urine protein in DN patients were significantly higher than those in normal diabetic patients. mAlb is a sensitive and reliable indicator for DN kidney injury, and was proven previously to be a vital reference indicator for DN diagnosis (19). Cys C, as an endogenous indicator, can freely filter through glomerulus and be reabsorbed and degraded in proximal convoluted tubules. $\mathrm{Cys} C \mathrm{C}$ is very sensitive to the early function of glomerulus and is also a sensitive indicator reflecting glomerular filtration function (20). However, 24-h proteinuria is one of the important indicators for judging glomerular function. When $24-\mathrm{h}$ proteinuria increases, it indicates further aggravation of metabolic disorder and kidney injury in vivo (21). Through correlation analysis of urine VDBP, serum miR-155-5p and the nephrotic sensitive indicators, it was discovered that urine VDBP, serum miR-155-5p and $\mathrm{mAlb}, \mathrm{Cys} \mathrm{C}$ and 24-h urine protein were positively correlated, which further indicated that the occurrence of urine VDBP, serum miR-155-5p and DN were relevant.

Subsequently, ROC analysis was carried out in order to study the diagnostic value of urine VDBP and serum
miR-155-5p for DN. ROC is currently a common method for evaluating the medical diagnostic efficiency. And the results demonstrated that although urine VDBP and serum miR-155-5p had good diagnostic value, the AUC of their joint detection for DN diagnosis was as high as 0.904 , which indicated that urine VDBP and serum miR-155-5p might be used as a new diagnostic mode for DN diagnosis. Previous studies (22) reported that miR-155-5p was highly expressed in renal tissues of DN patients, and its expression gradually increased with the progression of the disease, which revealed that it might also be tied to disease progression. Once entering stage ESRD, DN patients become more difficult to treat, and their condition will be almost impossibile to reverse, which also indicates poor prognosis (23). Therefore, patients were divided into ESRD group and non-ESRD group according to the follow-up situation, and the predictive value of urine VDBP and serum miR-155-5p was analyzed for poor prognosis of DN patients; the results showed that urine VDBP had higher sensitivity to poor prognosis of DN patients than serum miR-155-5p, but the sensitivity was the highest when joint detection was performed, and the diagnostic AUC could be as high as 0.886 , which indicated that the joint detection of urine VDBP and serum miR-155-5p also had higher predictive value for their poor prognosis. This was also the first time that the joint detection of urine VDBP and serum miR-155-5p was found to have good predictive value for the onset and prognosis of DN.

In conclusion, urine VDBP and serum miR-155-5p have good diagnostic value for $\mathrm{DN}$, but their joint diagnostic value is higher, and their expression levels are all linked to $\mathrm{mAlb}$ of DN patients, which may be used as new biological indicators for diagnosis and disease assessment. However, we did not further analyze the risk factors for poor prognosis of DN 
patients, nor did we conduct relevant basic experiments to clarify the effects of VDBP and miR-155-5p on the kidneys. Therefore, further study with expanded sample numbers is still required.

\section{Acknowledgements}

Not applicable.

\section{Funding}

The study was supported by the Nephrology Research Center of East Zhejiang (Zhejiang Health Commission 2015, no. 21) and the 'Ningbo City Focuses on Fostering Disciplines' project (no. 2016022).

\section{Availability of data and materials}

The datasets used and/or analyzed during the present study are available from the corresponding author on reasonable request.

\section{Authors' contributions}

XB and LG conceived and designed the study. XB, QL, KT and LG were responsible for the acquisition, analysis and interpretation of the data. XB drafted the manuscript. QL revised the manuscript critically for important intellectual content. All authors read and approved the final manuscript.

\section{Ethics approval and consent to participate}

The study was approved by the Ethics Committee of HwaMei Hospital (Ningbo, China). Signed informed consents were obtained from the patients and/or guardians.

\section{Patient consent for publication}

Not applicable.

\section{Competing interests}

The authors declare that they have no competing interests.

\section{References}

1. Zhuang L, Jin G, Hu X, Yang Q and Shi Z: The inhibition of SGK1 suppresses epithelial-mesenchymal transition and promotes renal tubular epithelial cell autophagy in diabetic nephropathy. Am J Transl Res 11: 4946-4956, 2019.

2. Coskun ZM, Ersoz M, Adas M, Hancer VS, Boysan SN, Gonen MS and Acar A: Kruppel-like transcription factor-4 gene expression and DNA methylation status in type 2 diabetes and diabetic nephropathy patients. Arch Med Res 50: 91-97, 2019.

3. Jiang S, Yu T, Zhang Z, Fang J, Wang Y, Yang Y, Liu L, Zou G, Gao H, Zhuo L, et al: Prognostic nomogram and score to predict renal survival of patients with biopsy-proven diabetic nephropathy. Diabetes Res Clin Pract 155: 107809, 2019.

4. Grujicic M, Salapura A, Basta-Jovanovic G, Figurek A, Micic-Zrnic D and Grbic A: Non-diabetic kidney disease in patients with type 2 diabetes mellitus - 11-year experience from a single center. Med Arh 73: 87-91, 2019.

5. Fawzy MS and Beladi FI: Association of circulating vitamin D, VDBP, and vitamin D receptor expression with severity of diabetic nephropathy in a group of Saudi type 2 diabetes mellitus patients. Clin Lab 64: 1623-1633, 2018.
6. Mirković K, Doorenbos CR, Dam WA, Lambers Heerspink HJ, Slagman MC, Nauta FL, Kramer AB, Gansevoort RT, van den Born J, Navis G, et al: Urinary vitamin D binding protein: A potential novel marker of renal interstitial inflammation and fibrosis. PLoS One 8: e55887, 2013.

7. Gu J, Huang W, Zhang W, Zhao T, Gao C, Gan W, Rao M, Chen Q, Guo M, Xu Y, et al: Sodium butyrate alleviates high-glucose -induced renal glomerular endothelial cells damage via inhibiting pyroptosis. Int Immunopharmacol 75: 105832, 2019.

8. Ebadi Z, Moradi N, Kazemi Fard T, Balochnejadmojarrad T, Chamani E, Fadaei R and Fallah S: Captopril and spironolactone can attenuate diabetic nephropathy in Wistar rats by targeting microRNA-192 and microRNA-29a/b/c. DNA Cell Biol 38: 1134-1142, 2019.

9. Shi Q, Zhang Y, Liu W, Xiao H, Qi Y, Li J and Luo B: Latent membrane protein $2 \mathrm{~A}$ inhibits expression level of Smad2 through regulating miR-155-5p in EBV-associated gastric cancer cell lines. J Med Virol 92: 96-106, 2020.

10. Wang J, Wang G, Liang Y and Zhou X: Expression profiling and clinical significance of plasma microRNAs in diabetic nephropathy. J Diabetes Res 2019: 5204394, 2019.

11. Xie J, Wang X, Zhang Y, Li H, Xu Y and Zheng D: The longitudinal effect of subclinical hypothyroidism on urine microalbumin-to-urine creatinine ratio in patients with type 2 diabetes mellitus. BMC Endocr Disord 19: 84, 2019.

12. Krueger DA, Northrup H, Northrup H, Krueger DA, Roberds S, Smith K, Sampson J, Korf B, Kwiatkowski DJ, Mowat D, et al; International Tuberous Sclerosis Complex Consensus Group: Tuberous sclerosis complex surveillance and management: Recommendations of the 2012 International Tuberous Sclerosis Complex Consensus Conference. Pediatr Neurol 49: 255-265, 2013.

13. Kocak MZ, Aktas G, Erkus E, Duman TT, Atak BM and Savli H: Mean platelet volume to lymphocyte ratio as a novel marker for diabetic nephropathy. J Coll Physicians Surg Pak 28: 844-847, 2018.

14. Prabu P, Rome S, Sathishkumar C, Gastebois C, Meugnier E, Mohan V and Balasubramanyam M: MicroRNAs from urinary extracellular vesicles are non-invasive early biomarkers of diabetic nephropathy in type 2 diabetes patients with the 'Asian Indian phenotype'. Diabetes Metab 45: 276-285, 2019.

15. Fawzy MS and Abu AlSel BT: Assessment of vitamin D-binding protein and early prediction of nephropathy in type 2 Saudi diabetic patients. J Diabetes Res 2018: 8517929, 2018.

16. Shoukry A, Bdeer S-A and El-Sokkary RH: Urinary monocyte chemoattractant protein-1 and vitamin D-binding protein as biomarkers for early detection of diabetic nephropathy in type 2 diabetes mellitus. Mol Cell Biochem 408: 25-35, 2015.

17. Tian XQ, Zhao LM, Ge JP, Zhang Y and Xu YC: Elevated urinary level of vitamin D-binding protein as a novel biomarker for diabetic nephropathy. Exp Ther Med 7: 411-416, 2014.

18. Akhbari M, Khalili M, Shahrabi-Farahani M, Biglari A and Bandarian F: Expression level of circulating cell free miR-155 gene in serum of patients with diabetic nephropathy. Clin Lab 65: 65, 2019.

19. Yang H, Xu W, Zhou Z, Liu J, Li X, Chen L, Weng J and Yu Z: Curcumin attenuates urinary excretion of albumin in type II diabetic patients with enhancing nuclear factor erythroid-derived 2-like 2 (Nrf2) system and repressing inflammatory signaling efficacies. Exp Clin Endocrinol Diabetes 123: 360-367, 2015.

20. Siddiqi Z, Karoli R, Kaul A, Fatima J, Varshney S and Beg MS: Evaluation of neutrophil gelatinase-associated lipocalin and cystatin $\mathrm{C}$ as early markers of diabetic nephropathy. Ann Afr Med 16: 101-106, 2017.

21. Liu R, Zhu H, Yang JH, Gao ZA, Yuan XX, Li XC, Wang JY and Chang BC: Can urine albumin/creatinine ratio replace 24 hs urinary albumin? Zhonghua Nei Ke Za Zhi 58: 377-381, 2019 (In Chinese).

22. Huang Y, Liu Y, Li L, Su B, Yang L, Fan W, Yin Q, Chen L, Cui T, Zhang J,et al: Involvement of inflammation-related miR-155 and miR-146a in diabetic nephropathy: Implications for glomerular endothelial injury. BMC Nephrol 15: 142, 2014.

23. Wang G, Ouyang J, Li S, Wang H, Lian B, Liu Z and Xie L: The analysis of risk factors for diabetic nephropathy progression and the construction of a prognostic database for chronic kidney diseases. J Transl Med 17: 264, 2019.

This work is licensed under a Creative Commons Attribution-NonCommercial-NoDerivatives 4.0 International (CC BY-NC-ND 4.0) License. 